\title{
ASPECTOS PERCEPTO-MOTORES E COGNITIVOS DO DESENVOLVIMENTO DE CRIANÇAS COM SÍNDROME DE DOWN
}

\author{
ASPECTS IN PERCEPTUAL-MOTOR DEVELOPMENT AND \\ SENSORY-MOTOR INTELLIGENCE IN DOWN SYNDROME
}

\author{
Livia Maria Marques Bonomo ${ }^{1}$ \\ Claudia Broetto Rossetti ${ }^{1}$
}

Bonomo LMM; Rossetti CB. Aspectos percepto-motores e cognitivos do desenvolvimento de crianças com Síndrome de Down. Rev. Bras. Cresc. e Desenv. Hum. 2010; 20(3) 723-734.

\section{Resumo:}

O desenvolvimento na Síndrome de Down ocorre com atraso quando comparado com o de crianças com desenvolvimento neuropsicomotor típico. Mas, estudos têm mostrado que a estimulação é importante no processo de desenvolvimento dessa população específica ao oferecer maiores oportunidades de experiências, minimizando as grandes defasagens associadas a ela. O objetivo é avaliar o desenvolvimento percepto-motor e cognitivo de crianças com Síndrome de Down, investigando a possível interdependência entre a motricidade e a estruturação intelectual. Participaram 10 crianças com síndrome de Down , com idade entre um e cinco anos. Para a coleta de dados foi utilizado um roteiro de observação do comportamento motor para descrever os padrões de locomoção, de manipulação, de estabilidade e de percepção, e provas piagetianas adaptadas para a descrição da construção das noções de objeto permanente, de causalidade física, de espaço e de tempo concernentes ao estágio sensório-motor do desenvolvimento cognitivo. Os itens referentes às duas avaliações foram categorizados de forma qualitativa a partir de critérios pré-estabelecidos. Os dados foram tratados utilizando análise estatística exploratória e descritiva. Observouse que os principais déficits motores e as maiores defasagens cognitivas foram apresentadas pelas crianças mais novas da amostra. Da mesma forma, uma maior interdependência na relação entre os diferentes itens avaliados ocorreu nesses mesmos participantes. Acreditase que, com o passar da idade, o processo de desenvolvimento dessas crianças tenda a se aproximar do que é tipicamente esperado, ratificando a importância das estimulações em longo prazo para as crianças com Síndrome de Down.

Palavras-chave: síndrome de Down; desenvolvimento infantil; desempenho Psicomotor; inteligência.

1 Universidade Federal do Espírito Santo - Av. Fernando Ferrari, 514 - CEMUNI VI - Goiabeiras CEP: 29075-910 - Vitória, ES. Programa de Pós-Graduação em Psicologia - Departamento de Psicologia Social e do Desenvolvimento/Universidade Federal do Espírito Santo

Correspondência para: Lívia Maria Marques Bonomo - Rua Dionísio Rozendo 125/203 - Centro - Vitória/ES CEP: 29010100 - E-mail: livia_bonomo@yahoo.com.br - Telefone: (27) 3322-0236/ (27) 8836-0816.

Trabalho financiado pelo Fundo de Apoio à Ciência e Tecnologia do Município de Vitória (FACITEC), sob o processo de número 018/2008.

Artigo baseado em dissertação de mestrado intitulada "Aspectos percepto-motores e cognitivos do desenvolvimento de crianças com Síndrome de Down do município de Vitória/ES”, defendida em 2010 na Universidade Federal do Espírito Santo. 


\begin{abstract}
:
The current literature states that the development in Down Syndrome occurs with delay when compared with that of children with typical neuropsychomotor development. But, studies have shown that stimulation is important in the process of development of this specific population by providing more opportunities for experience, possibly minimizing the large deficits associated with it. The present research aims to evaluate the perceptual, motor and cognitive development of children with Down Syndrome, investigating the possible interdependence between the motricity and the intelligence structuring. This research involved 10 children with Down Syndrome aged between one and five years. For data collection a structured observation of motor behavior to describe the patterns of locomotion, manipulation, stability, and perception was used, besides the adapted piagetian Clinical Method for observation and description of the construction of the concepts of permanent object, physical causality, space and time concerning the sensory-motor stage of cognitive development. The items related to both evaluations were categorized in a qualitative way from pre-established criteria. The data were processed using an exploratory and descriptive statistical analysis. It was observed that the major motor deficits and higher cognitive gaps were presented by the younger children in the sample. In the same way, the greatest interdependence in the relation among the different evaluated items occurred in these same children. It is believed that, with the passing of years, the development process of these children tends to get closer to what is typically expected, confirming the importance of long-term stimulation for children with Down Syndrome.
\end{abstract}

Key words: Down syndrome; child development; psychomotor performance; intelligence.

\section{INTRODUÇÃO}

Na infância, grandes habilidades motoras são adquiridas, proporcionando um maior controle corporal em diferentes movimentos e posturas usados em muitas tarefas de vida diária, de vida prática e de lazer ${ }^{1}$. As experiências nos primeiros anos de vida provocam a reorganização e o estabelecimento de novas conexões sinápticas e a formação de grandes redes neuronais que facilitam o processo de desenvolvimento ${ }^{2,3}$. Ao longo do processo de amadurecimento orgânico associado a oportunidades ambientais apropriadas, as crianças nos surpreendem com suas crescentes conquistas. Quanto mais habilidades aprendem, maior a exploração de outras possibilidades, e quanto maior essa exploração, mais aprendem a fazer ${ }^{2,4}$.

Dessa forma, o desenvolvimento motor se manifesta por modificações no comportamento motor ao longo da vida, de modo que aprendemos a nos mover com eficiência e a controlar e a nos adaptar às constantes altera- ções do meio. De acordo com Gallahue e Ozmun $^{5}$, as influências genéticas e ambientais são fundamentais para compreender o desenvolvimento. A sequência dos marcos motores é bem estabelecida, mas, seu ritmo de progressão é variável, uma vez que o surgimento de oportunidades adicionais para a prática associado a ambientes favoráveis ao aprendizado, facilita a aquisição das habilidades motoras. Trata-se de um processo dinâmico, devendo considerá-lo de maneira multidimensional, relacionando as grandes áreas do desenvolvimento humano (cognitivo, afetivo e motor) que operam sobre o próprio indivíduo e também sobre o ambiente.

Similarmente, a construção da inteligência se caracteriza por um processo contínuo de transformações graduais ao longo da vida. Para Piaget, as atividades intelectuais e biológicas participam da adaptação do homem ao meio e organizam as experiências adquiridas para manter a condição de totalidade frente às perturbações ambientais ${ }^{6,7}$. Assim, o conhecimen- 
to e, consequentemente, o desenvolvimento, surgem de interações contínuas entre o sujeito e o ambiente. O estágio sensório-motor é o início da construção intelectual e a criança se adapta funcionalmente e regula seus atos de acordo com as relações que estabelece com objetos e pessoas, utilizando as sensações, as percepções e as ações para isso ${ }^{7}$.

Portanto, a interação da criança com o ambiente é fundamental para a aquisição das habilidades cognitivas e o movimento é a base para essa interação. O conjunto das aptidões motoras, sociais e cognitivas permite à criança explorar o universo de maneira mais organizada. Logo, um atraso no desenvolvimento motor da criança pode se relacionar com um atraso nos demais campos, incluindo a estruturação da inteligência sensório-motora ${ }^{8-10}$.

A Síndrome de Down (SD) é uma condição genética muito conhecida e tem como característica um esperado atraso global do desenvolvimento. Porém, uma criança com SD é capaz de conquistar grande parte das habilidades motoras de uma criança com desenvolvimento típico, apesar do aparecimento provavelmente tardio das mesmas, podendo chegar ao dobro da idade média daquelas sem um déficit motor $^{11}$. Além disso, a falta de experiências físicas pode dificultar a exploração do ambiente que, associados a um déficit de integração sensorial e perceptiva de si mesmo, dos objetos e do espaço, interferem, em geral, no processo do desenvolvimento cognitivo dessa criança.

Dessa forma, o objetivo é avaliar os aspectos percepto-motores e cognitivos do desenvolvimento de crianças com Síndrome de Down.

\section{MÉTODO}

Participaram deste estudo qualitativo, 10 crianças com diagnóstico de SD, sem outra patologia associada, de ambos os sexos e com idades entre um a cinco anos.
O desenvolvimento percepto-motor foi avaliado pela descrição detalhada do comportamento, mostrando não só o que a criança é capaz de fazer, mas como ela faz, o que permitiu explorar ao máximo as habilidades perceptomotoras e suas diversas interações com outros aspectos do desenvolvimento.

Dessa forma, foi realizada a observação de comportamentos relativos às categorias de movimento - locomoção, manipulação e estabilidade - e à categoria de percepção, fundamentada na obra de Gallahue e Ozmun ${ }^{5}$.

Cada categoria continha itens específicos com as principais habilidades da criança pequena. Na categoria locomoção, as habilidades avaliadas foram o arrastar, a locomoção sentada, o engatinhar, a marcha e a corrida.

A categoria de manipulação incluiu itens relativos à avaliação do alcance, da preensão e da soltura. Na categoria estabilidade, observouse o equilíbrio estático na postura sentada, de pé e em um só pé, e o equilíbrio dinâmico durante as transições de posturas e a marcha direcionada sobre linha de $10 \mathrm{~cm}$. E, por fim, na categoria da percepção, os itens avaliaram a percepção visual (capacidade de seguir deslocamentos do objeto, visão periférica e coordenação viso-motora), a percepção auditiva (reage e procura a fonte sonora) e a percepção corporal (imitação e identificação das partes do corpo).

As habilidades eram descritas e posteriormente comparadas com os padrões esperados para uma criança com desenvolvimento típico na mesma faixa etária do participante, sendo classificadas em atrasada, adequada ou adiantada para a idade cronológica.

O estágio sensório-motor do desenvolvimento cognitivo foi avaliado pela aquisição das noções de objeto permanente, de espaço, de causalidade física e de tempo através de provas baseadas no método clínico, preconizado por Jean Piaget. "O Método Clínico é um procedimento para investigar como as crianças pensam, percebem, agem e sentem, que 
procura descobrir $[\ldots]$ o que está por trás da aparência de sua conduta" ${ }^{12}$. Tem como característica principal a intervenção sistemática do experimentador frente ao comportamento do sujeito, colocando em prática uma série de intervenções, para a compreensão das ações da criança que confirmarão ou não as hipóteses do estudo ${ }^{12}$.

As provas das quatro noções sensoriomotoras, buscaram, por meio da fundamentação teórica apresentada, esclarecer a forma como a criança compreende o mundo através das noções de:

a) objeto permanente, que avalia a compreensão da criança sobre a constância na forma, na aparência e na existência de objetos independentes dela própria, através de sete tarefas sobre os diversos tipos de deslocamentos (visíveis e invisíveis, simples e complexos) e a busca de objetos por trás de variados anteparos;

b) espaço, que mostra, através de seis tarefas, a relação entre os objetos existentes (por exemplo, relação de conteúdo e continente usando caixas e objetos de diversos tamanhos) e entre os objetos e a própria criança (por exemplo, tarefa de desvios no ambiente para recuperar objeto distante e reversão de objetos, como copo com bico e lápis, para utilizar lado funcional) num espaço comum;

c) causalidade física, que avalia a capacidade do participante em entender a conexão física entre objetos, a relação entre causa e efeito dos fenômenos (realizados tanto com brinquedos quanto com o próprio corpo do examinador) e a possibilidade de construção de novos meios para se chegar a um objetivo (uso de corda e vara para alcançar o objeto) através de onze tarefas;

d) e tempo, que revela como a criança compreende o curso temporal dos acontecimentos externos, pela realização de sete tarefas englobando habilidades mnemônicas sobre lugar, deslocamento e fatos remotos.

Foram utilizados objetos como fraldas, brinquedos de diferentes tamanhos, caixa me- nor, caixa maior com dois orifícios, brinquedo mecânico, vara, duas cordas, almofadas, copos com bico, lápis, e outros objetos que se encontravam no ambiente de avaliação. A elaboração das diversas tarefas foi baseada nas observações descritas por Piaget em suas obras ${ }^{13,14}$. Também foram consultadas a obra de Carraher ${ }^{15}$ para a avaliação da noção de objeto permanente e a escala de Uzgiris e Hunt ${ }^{16}$ que propõe uma avaliação psicológica para o bebê baseada na teoria piagetiana.

Cada tarefa referente às quatro noções do estágio sensório-motor foi classificada em ausente, quando o comportamento esperado não era observado em várias tentativas; em construção, quando a criança mostrava ora o comportamento adequado, ora não; e presente, quando a resposta era visivelmente observada pelo examinador logo nas primeiras aplicações das tarefas.

Cruzando-se, posteriormente, os dados de tais tarefas, cada noção recebeu uma atribuição em diferentes subestágios ou transições entre os subestágios seguindo critérios pré-estabelecidos, baseados pelo proposto por Piaget ${ }^{13}$. Para verificar se houve relação entre os dados das duas avaliações, os resultados dos itens avaliados foram cruzados e exibidos aqui por meio de descrições das observações.

A pesquisa foi aprovada pelo Comitê de Ética em Pesquisa da Universidade Federal do Espírito Santo sob o protocolo 058/09. Um termo de consentimento, livre e esclarecido foi preenchido pelos responsáveis legais das crianças, após uma explicação detalhada dos procedimentos empregados na coleta dos dados.

\section{RESULTADOS}

Do total de participantes, cinco eram do sexo feminino e cinco do sexo masculino, com idades variando entre 1 ano e 5 meses e 4 anos e 11 meses. 
Tabela1: Desempenho dos participantes nas habilidades motoras da categoria locomoção.

\begin{tabular}{llc}
\hline Habilidades de Estabilidade estática & \\
Sentado & Atrasado para a idade & 2 \\
& Adequado para a idade & 8 \\
De pé & Atrasado para a idade & 3 \\
& Adequado para a idade & 7 \\
Em um só pé & Atrasado para a idade & 5 \\
& Adequado para a idade & 1 \\
Estabilidade dinâmica & Não avaliado* & 4 \\
Transição de posturas & & 4 \\
& Atrasado para a idade \\
Marcha sobre linha $10 \mathrm{~cm}$ & Adequado para a idade & 6 \\
& Atrasado para a idade \\
& Adequado para a idade & 9 \\
$*$ Idade cronológica do participante não compatível com idade esperada para a aquisição da \\
habilidade
\end{tabular}

Tabela 2: Desempenho dos participantes nas habilidades motoras da categoria locomoção

\begin{tabular}{llr}
\hline Habilidades Locomotoras & & $\mathbf{n}$ \\
Arrastar & Atrasado para a idade & 0 \\
& Adequado para a idade & 10 \\
Locomoção sentada & Atrasado para a idade & 0 \\
\multirow{2}{*}{ Engatinhar } & Adequado para a idade & 10 \\
& Atrasado para a idade & 1 \\
Marcha & Adequado para a idade & 9 \\
& Atrasado para a idade & 7 \\
\hline
\end{tabular}

Tabela 3: Desempenho dos participantes nas habilidades motoras da categoria manipulação

\begin{tabular}{lll}
\hline Habilidades Manipulativas & n \\
Alcance & Atrasado para a idade & 2 \\
& Adequado para a idade & 8 \\
Preensão & Atrasado para a idade & 4 \\
& Adequado para a idade & 6 \\
Soltura & Atrasado para a idade & 4 \\
& Adequado para a idade & 6 \\
Corrida & Atrasado para a idade & 9 \\
& Adequado para a idade & 0 \\
& Não avaliado* & 1 \\
\hline
\end{tabular}

* Idade cronológica do participante não compatível com idade esperada para a aquisição da habilidade. 
Tabela 4: Desempenho dos participantes nas habilidades da categoria percepção.

\begin{tabular}{|c|c|c|c|c|c|}
\hline \multicolumn{3}{|c|}{$\begin{array}{l}\text { Habilidades Perceptivas } \\
\text { Percepção visual e coordenação viso-motora }\end{array}$} & $\begin{array}{l}\text { Atrasado para a } \\
\text { Adequado para }\end{array}$ & & $\begin{array}{l}\mathbf{n} \\
2 \\
8\end{array}$ \\
\hline \multicolumn{3}{|c|}{ Percepção auditiva } & $\begin{array}{l}\text { Atrasado para a } \\
\text { Adequado para a }\end{array}$ & & $\begin{array}{r}0 \\
10\end{array}$ \\
\hline \multicolumn{3}{|c|}{ Percepção corporal } & $\begin{array}{l}\text { Atrasado para a } \\
\text { Adequado para }\end{array}$ & & $\begin{array}{l}3 \\
7\end{array}$ \\
\hline \multicolumn{5}{|c|}{ Total } & 10 \\
\hline & Idade & Objeto permanente & Noção de espaço & Causalidade física & Tempo \\
\hline C1 & $1 \mathrm{a} 5 \mathrm{~m} \mathrm{1d}$ & $5^{\circ}$ subestágio & $4^{\circ} / 5^{\circ}$ subestágio & $3^{\circ} / 4^{\circ}$ subestágio & $4^{\circ} / 5^{\circ}$ subestágio \\
\hline $\mathrm{C} 2$ & 2a $3 \mathrm{~m} \mathrm{10d}$ & $5 / 6^{\circ}$ subestágio & $4^{\circ} / 5^{\circ}$ subestágio & $3^{\circ} / 4^{\circ}$ subestágio & $4^{\circ} / 5^{\circ}$ subestágio \\
\hline $\mathrm{C} 3$ & 2a $3 \mathrm{~m} 12 \mathrm{~d}$ & $5 / 6^{\circ}$ subestágio & $4^{\circ} / 5^{\circ}$ subestágio & $4^{\circ} / 5^{\circ}$ subestágio & $4^{\circ} / 5^{\circ}$ subestágio \\
\hline $\mathrm{C} 4$ & $2 \mathrm{a} 8 \mathrm{~m} 7 \mathrm{~d}$ & $5 / 6^{\circ}$ subestágio & $5 / 6^{\circ}$ subestágio & $4^{\circ} / 5^{\circ}$ subestágio & $4^{\circ} / 5^{\circ}$ subestágio \\
\hline C5 & 3a $18 d$ & $5 / 6^{\circ}$ subestágio & $5 / 6^{\circ}$ subestágio & $4^{\circ} / 5^{\circ}$ subestágio & $5^{\circ} / 6^{\circ}$ subestágio \\
\hline C6 & 3a $9 \mathrm{~m} \mathrm{16d}$ & $6^{\circ}$ subestágio & $6^{\circ}$ subestágio & $5^{\circ} / 6^{\circ}$ subestágio & $5^{\circ} / 6^{\circ}$ subestágio \\
\hline C7 & $4 \mathrm{a} 6 \mathrm{~m}$ & $6^{\circ}$ subestágio & $6^{\circ}$ subestágio & $6^{\circ}$ subestágio & $6^{\circ}$ subestágio \\
\hline C8 & $4 \mathrm{a} 6 \mathrm{~m}$ & $6^{\circ}$ subestágio & $6^{\circ}$ subestágio & $5 / 6^{\circ}$ subestágio & $6^{\circ}$ subestágio \\
\hline C9 & 4a $7 \mathrm{~m} \mathrm{21d}$ & $5 / 6^{\circ}$ subestágio & $5 / 6^{\circ}$ subestágio & $5 / 6^{\circ}$ subestágio & $5^{\circ} / 6^{\circ}$ subestágio \\
\hline C10 & 4a $11 \mathrm{~m} 25 \mathrm{~d}$ & $6^{\circ}$ subestágio & $6^{\circ}$ subestágio & $5 / 6^{\circ}$ subestágio & $6^{\circ}$ subestágio \\
\hline
\end{tabular}

\section{DISCUSSÃO}

Muito se tem publicado, nos últimos anos, sobre o comum atraso motor em crianças com SD. A hipotonia muscular tem sido considerada uma das principais causas das alterações motoras encontradas nesses indivíduos, pois tende a diminuir a exploração do ambiente e o desenvolvimento de suas habilidades $^{8,10,17}$. No presente estudo, foram percebidos alguns atrasos nos padrões apresentados pelas crianças com SD quando comparadas com o que se espera para uma criança com desenvolvimento típico (tabela 1 a 4), principalmente nas habilidades mais complexas de cada categoria.

Quanto ao desenvolvimento cognitivo, sabe-se que a deficiência mental é um quadro bastante encontrado e variável nesta síndrome, com uma larga extensão das funções cognitivas para cada criança ${ }^{18}$. A avaliação do estágio sensório-motor proporcionou tomar conhecimento sobre a psicogênese da inteligência sensório-motora nas crianças com SD aqui avaliadas. O desenvolvimento deste estágio cognitivo, avaliado de acordo com a teoria piagetiana, também apresentou defasagens nos participantes, com atrasos na aquisição das quatro diferentes noções relacionadas ao mesmo (tabela 5).

A literatura tem descrito as possíveis interdependências entre essas áreas do desenvolvimento no funcionamento global do indivíduo.

No presente estudo, as maiores relações de defasagens foram encontradas nas crianças mais novas da amostra. Na categoria locomoção, os atrasos nas habilidades de marcha e de corrida apresentaram relações mais próximas com o atraso nas tarefas cognitivas das quatro noções do estágio sen- 
sório-motor. O retardo na aquisição e os padrões errôneos no caminhar e no correr podem interferir na construção cognitiva, pois possivelmente pouco oportuniza a busca de objetos distantes e o conhecimento sobre a profundidade e o espaço que o corpo ocupa no meio ${ }^{8}$. Além disso, a movimentação tardia da criança com SD tende a dificultar a descoberta de novas situações e da conexão entre os objetos que a rodeiam:

C1: No uso da corda para obter objeto, ora tenta buscá-lo diretamente, sem sucesso, ora explora a corda e, vendo o objeto se mover, balança-a ainda mais.

C2: $1^{\text {a }}$ tentativa: coloco o brinquedo longe e as duas cordas acessíveis a ela. Ela puxa a corda correta, mas brinca com a mesma. $2^{a}$ tentativa: olha para o brinquedo e aponta para o mesmo. Tenta ir diretamente, mas desiste. Olha irritada para a examinadora. Pergunto: e agora? Ela ignora as cordas e vai diretamente ao brinquedo.

C3: Na prova de suporte, criança varia os comportamentos entre apontar para o brinquedo, pegá-lo diretamente ou puxar o suporte para alcançar o objeto.

Para além, a falta de movimento pode restringir, nessas crianças, as descobertas acerca do espaço e do seu conteúdo, tornando frágil a construção das noções sensório-motoras:

C2: A criança visualiza a trajetória da bola sob obstáculo. Olha acima do mesmo e depois para o caminho percorrido pela bola, apontando para ela. Quando incentivo a buscála, tenta percorrer o mesmo trajeto que a bola, por baixo do obstáculo, engatinhando, mas para no meio do caminho.

C3: Desloco o objeto em A, B, C e D. Ela acompanha com o olhar até D e aponta, mas sem busca ativa. Após apontar para o brinquedo e ver que ele não apareceu, procura sob B como se o objeto pudesse voltar para este anteparo.

A locomoção resulta na mudança de perspectiva do ambiente, mostrando que relações espaciais puramente egocêntricas não colaboram, unicamente, na localização de objetos escondidos ${ }^{13,19}$. Pesquisas mostram que bebês com capacidade locomotiva são melhores em encontrar brinquedos escondidos, uma vez que a locomoção é funcionalmente interligada às condutas cognitivas infantis, pois promove a maturação do cérebro, facilita a compreensão da inter-relação entre os objetos e proporciona um melhor desempenho na busca de materiais distantes ${ }^{20,21}$.

As crianças com SD costumam exibir um atraso no início das atividades locomotoras, o que influencia na exploração precoce do ambiente e no aprendizado contínuo sobre o universo ${ }^{9}$. Por isso, suporte e mais prática são necessários para que essas diferenças não se tornem consistentes ao longo dos anos. Nossos dados se inclinam para esta tendência. Alguns dos sujeitos, de idades superiores que apresentaram alterações nos padrões de marcha, mas não se relacionaram com grandes defasagens nas tarefas cognitivas quando comparadas aos mais novos da amostra. Este fato supõe que a maior oportunidade de experiências em diferentes contextos pode ter permitido a aprendizagem de estratégias de adaptação frente às novas demandas, colaborando na capacidade de solucionar os problemas propostos.

Similarmente, o atraso encontrado nas habilidades manipulativas se relacionou com as tarefas cognitivas referentes aos últimos subestágios sensório-motores, nas crianças mais novas da amostra. A mão é essencial no desenvolvimento cognitivo. Com a conquista da preensão, os comportamentos ganham intencionalidade e a criança passa a tomar maior conhecimento sobre ela própria, sobre as propriedades das coisas ao seu redor e sobre o mundo externo. É o contato com o objeto que proporciona a construção gradativa de um universo organizado, o que torna a criança funcional dentro dele ${ }^{14}$.

Portanto, alterações nessa habilidade podem prejudicar fortemente o desenvolvimento global da criança: 
C4: Após retirar todas as contas do recipiente, tenta colocá-las de duas em duas com o uso de uma das mãos. Mas não consegue e as contas caem ao chão. Além disso, frente a um espetáculo com um boneco, durante a pausa, tenta ativálo por conta própria, imitando o meu gesto percebido como eficaz. Porém, é difícil envolver com suas mãos o boneco e apertá-lo para que repita o som. Impaciente, repete ações relativas às reações circulares secundárias para tentar reativálo, como batê-lo ao chão e sacudi-lo.

$\mathrm{O}$ quadro motor característico da SD dificulta o uso das mãos e o controle durante o manuseio de objetos. Com isso, as crianças tendem a manipular e explorar menos, interferindo na aprendizagem sobre as propriedades do universo à sua volta ${ }^{8,22}$. Padrões semelhantes foram observados nas crianças $\mathrm{C} 1, \mathrm{C} 2$ e C3:

C1: Para reativar o brinquedo mecânico após demonstração, tenta, com os dedos, apertar a barriga da boneca para repetir o espetáculo, onde se encontrava o botão de ativação, mas não consegue e retorna às reações circulares secundárias.

C2: Criança não consegue permanecer segurando objetos grandes para colocar em um dos orifícios da caixa. Eles caem de suas mãos em várias tentativas, o que a irrita e a faz desistir da tarefa.

C3: Repete sempre o mesmo padrão de retirar/colocar uma conta por vez da caixinha. Não varia o movimento na tarefa. Da mesma forma, a pobreza dessa habilidade é vista na tarefa da caixa com dois orifícios, tentando sempre encaixar os objetos num mesmo buraco, independente do tamanho deles.

Assim, as dificuldades motoras estiveram presentes durante a execução das tarefas sensório-motoras, entre elas: falta de força, dificuldade em segurar objetos grandes ou dois objetos numa mesma mão pelo tamanho reduzido da superfície de contato e a pouca variedade nos padrões de exploração manual dos objetos, que possivelmente resultou em uma pobre percepção da relação espacial entre os mesmos.
A aprendizagem da motricidade fina na SD é caracterizada por lentidão, dificuldade e pouco controle do movimento, o que foi encontrado nas crianças que apresentaram déficits motores. As atividades manipulativas requerem precisão, atenção e habilidades sensoriais e perceptivas adequadas, qualidades provavelmente encontradas com alguma deficiência nessas crianças ${ }^{23}$.

Também foi observado que as crianças na faixa etária de três a cinco anos apresentaram menores defasagens nas tarefas sensóriomotoras. As maiores dificuldades manipulativas, na criança com SD, são visíveis nos primeiros anos de vida. A prática de diversas atividades que utilizam a manipulação permite uma melhora da coordenação fina para que possam realizar com maior eficiência ações comuns da vida diária ${ }^{22}$. É possível que a estimulação constante e as diferentes possibilidades de contatos com objetos favoreçam uma melhor resposta motora durante as tarefas.

Quando consideramos a estabilidade estática e dinâmica, os maiores déficits do equilíbrio foram relacionados às tarefas sensóriomotoras de maior complexidade e associados às crianças mais novas. Não foram consistentemente estabelecidas relações de atraso entre o equilíbrio estático em um só pé e durante a marcha direcionada e as tarefas sensório-motoras avaliadas, talvez pelo fato de que estas não exigiam o uso de tais habilidades.

O equilíbrio é a base para a movimentação corporal e pode ser considerado como compensações das diferentes forças que atuam sobre o corpo, tendo importância o tônus postural e o sistema neuromuscular na organização das perturbações sobre uma base de apoio adequada em qualquer postura e durante a movimentação ${ }^{24}$.

A hipotonia e a fraqueza muscular, as lentidões no processamento das informações e na resposta motora e as alterações sensoriais comumente associadas à SD podem prejudicar sua capacidade em manter uma estabilida- 
de adequada. Consequentemente, os movimentos tendem a ser alterados, com um consumo exagerado de energia para a manutenção postural e para o controle motor e fadiga de todo o organismo, resultando em sentimentos de estresse, ansiedade e frustração frente às demandas das tarefas e do ambiente ${ }^{24}$, quadro encontrado aqui. As crianças que mostraram grandes dificuldades em se manterem estáveis apresentaram repertório de movimentos pobres que dificultaram a realização das tarefas cognitivas:

C1: Olha para objeto do outro lado, por baixo do obstáculo. Tenta, engatinhando com dificuldade e desequilíbrio, pegá-lo pela mesma trajetória que percorreu, mas desiste. Olha por mais tempo para o brinquedo. Tenta novamente, se arrastando por baixo do obstáculo. Não consegue, perdendo constantemente sua estabilidade. Se irrita, começa a bater no chão e se volta para os pais.

C2: No uso da vara, a criança olha para dentro do pote. Pega a vara, mas rapidamente descarta-a e tenta retirar com os dedos, apesar da grande dificuldade em manter o pote com uma mão e retirar objetos com a outra.

C3: Acompanha o movimento do objeto sob o anteparo. Olha para mim, aponta para a fralda e exprime: Oh!. Vendo que não retiro a fralda, tenta agir levantando-a e vendo o objeto sob ela. Em seguida repete o apontar e a expressão. Tenta retirar a fralda, mas não consegue. Após muita insistência, consegue retirar a fralda. No deslocamento invisível complexo, ela busca sempre no anteparo do meio, após procurar na mão da examinadora, pois é esta fralda que está a sua frente. É importante notar que um dos braços sempre se manteve elevado para ajudar na manutenção do equilíbrio e movimentos do tronco foram constantemente observados.

A evolução do controle postural está associada a uma aquisição sequencial de atos motores importantes como rolar, sentar, engatinhar, ficar em pé e andar e, antes do movi- mento voluntário ocorrer, existe uma antecipação desse controle para minimizar possíveis alterações do equilíbrio. Portanto, as funções de mobilidade e manipulação podem mostrar limitações em casos de anormalidades da estabilidade ${ }^{25}$.

Uma postura estável sentada, sem apoio, permite o uso e a coordenação das mãos no manuseio dos objetos ${ }^{26}$. Thelen, Corbetta e Spencer ${ }^{27}$, avaliando lactentes de 6-7 meses, mostraram que o alcance está associado ao refinamento do equilíbrio axial. Samsom e Groot $^{28}$ analisaram 75 lactentes pré-termo de alto risco e concluíram que um controle postural deficiente tende a influenciar o desenvolvimento das funções manuais, de mobilidade e de simetria corporal.

É assim que a criança $\mathrm{C} 1$ deixa de conhecer sobre o espaço e as relações, ao perder o equilíbrio e não conseguir engatinhar pelo obstáculo para recuperar o brinquedo. Também como a criança $\mathrm{C} 2$, que, mesmo mantendo uma postura inadequada de equilíbrio para tentar a coordenação manual, não aprende sobre a conexão entre objetos como meios e fim pelas constantes perturbações. $\mathrm{E}$ a criança $\mathrm{C} 3$, que demora em descobrir o objeto sob anteparo pela dificuldade em manter o equilíbrio do corpo para a preensão do obstáculo.

$\mathrm{Na}$ análise da associação entre as habilidades perceptivas e cognitivas dessas crianças, quanto à percepção visual, duas crianças apresentaram relações de atraso entre esta e a maior parte das tarefas cognitivas. A visão é fundamental para a maioria de nossas ações. Se apreendemos um objeto, nossos olhos se voltam para ele. Se quisermos correr, caminhar ou pular, nossa visão examina as demandas para essas habilidades ${ }^{29}$. As condutas propriamente inteligentes se iniciam com a coordenação entre a visão e a preensão, possibilitando a exploração do corpo, dos objetos e do meio ${ }^{30}$.

Quaisquer alterações visuais podem acarretar mudanças na percepção espacial, na locomoção independente e na exploração ma- 
nual. $\mathrm{Na}$ SD, alguns achados oftalmológicos como problemas de refração, nistagmo congênito e diminuição na acuidade visual tendem a dificultar o uso das informações visuais para adequar o movimento antecipadamente à sua execução. Além disso, a lentidão no seguimento dos objetos e a visão periférica reduzida podem comprometer o desenvolvimento da visão espacial, importante para a noção espacial, e a fixação visual, fundamental na análise e na compreensão das demandas da tarefa e do ambiente $^{31-34}$.

$\mathrm{Na} \mathrm{SD}$, as alterações da percepção visual e a lentificação no processamento das informações aferentes colaboram com quadros de desatenção, desmotivação e de retardo da conquista de importantes marcos. A manutenção do olhar pode parecer frágil nessas crianças principalmente nos primeiros anos de vida, em que as dificuldades motoras são mais evidentes, como encontrado aqui ${ }^{17}$.

Um padrão similar foi observado quanto à percepção corporal. As crianças que exibiram atrasos nesta habilidade mostraram maiores defasagens nas tarefas cognitivas. A imagem corporal traduz o equilíbrio entre as relações do organismo e do ambiente. Os contatos iniciais que a criança utiliza para entender o que se passa à sua volta são aqueles estabelecidos com o próprio corpo, para depois iniciar o contato com o exterior, e organizar suas próprias sensações com os dados do meio, permitindo movimentações e a construção gradativa do mundo externo ${ }^{24,14}$.

Assim, a construção da percepção corporal é solidária à construção da mobilidade da criança. Quanto mais se movimenta, mais percebe a si mesmo e, quanto melhor o conhecimento de si mesmo, mais efetivas são suas ações sobre o ambiente, o que relaciona essas três dimensões (percepção corporal, motricidade e cognição):

$\mathrm{C} 1$ : coloca as duas mãos na caixinha $\mathrm{e}$ faz movimentos com os dedos, para retirar as contas, mas sem sucesso pela incoordenação.
Não sistematiza o retirar e o colocar. Ao mesmo tempo em que coloca, faz movimentos para tentar retirar da caixinha.

C3: Jogo uma bola através de um brinquedo no parquinho (tipo um túnel). Ela acompanha o movimento e aponta com o dedo para a bola do outro lado. Se agacha e engatinha para dentro do túnel, seguindo a mesma trajetória da bola, mas sem completar o caminho. Não desvia do brinquedo para se dirigir ao lado oposto.

C4: nas duas primeiras tentativas, a criança, de pé, não percebe a corda e vai buscar diretamente o objeto. Numa $3^{\text {a }}$ tentativa, quando coloco o objeto mais longe, puxa o mesmo pela corda e ativa-o. Mas, às vezes, ainda vai diretamente ao brinquedo.

A primeira criança tem dificuldade em perceber a relação dos movimentos manuais com os objetos que manipula na caixa, o que provavelmente obstaculiza as operações sobre a noção espacial. A criança $\mathrm{C} 3$ exibiu uma percepção corporal frágil e, consequentemente, uma deficiente colocação dela no meio, o que interfere na reflexão sobre o que pode realizar para facilitar a recuperação do objeto. Por fim, na criança $\mathrm{C} 4$, ao considerarmos a percepção resultante da congruência de todas as informações internas e externas, vimos uma relação possivelmente defasada. Num processo de desenvolvimento típico, seria esperada, nessa idade, uma análise de toda a situação e o uso da corda como meio para alcançar o objeto. Ou seja, a criança imagina as relações existentes no contexto e se coloca de maneira a executar da melhor forma a tarefa, o que não foi exibido pela criança em questão.

Sendo assim, a partir de todos os dados coletados, foi possível concluir que os aspectos percepto-motores de crianças com SD podem interferir na construção de sua inteligência prática, o que foi encontrado principalmente nas crianças mais novas da amostra. A oportunidade de vivências experimentadas ao longo dos anos, associada à maior maturação neuro- 
lógica, tende a facilitar a aproximação do seu desenvolvimento com o das crianças sem qualquer prejuízo.

$\mathrm{Na}$ presente pesquisa, optou-se pelo uso de avaliações descritivas, classificando o desenvolvimento motor dos sujeitos por meio da análise da qualidade dos movimentos e dos padrões esperados de acordo com as idades que apresentavam. Apesar de tal metodologia não ser comumente empregada nos estudos atuais, acreditamos que ela tem sua importância científica ao permitir uma avaliação meticulosa dos aspectos relevantes ao estudo e por se assemelhar à teoria construtivista de Jean Piaget. Sabe-se que o movimento é fundamental na maturação orgânica, pois nos torna funcional no ambiente, facilitando a compreensão daquilo que nos envolve. Com base nesses pressupostos, focamos na avaliação do estágio sensóriomotor dessas crianças, utilizando o método clínico piagetiano para observar o processo do desenvolvimento cognitivo.

Encontrou-se como resultado um atraso no desenvolvimento motor dos participantes, com prejuízos mais observados nas habilida-

\section{REFERÊNCIAS}

1. Santos S, Dantas L, Oliveira JA. Desenvolvimento motor de crianças, de idosos e de pessoas com transtornos da coordenação. Rev paul Educ Fís. 2004; 18:33-44. N. esp.

2. Flehmig I. Texto e Atlas do desenvolvimento normal e seus desvios no lactente: diagnóstico e tratamento precoce do nascimento até o $18^{\circ}$ mês. São Paulo: Atheneu, 2000.

3. Denucci SM, Catanho EG. Desenvolvimento motor. In: Braga LW; Paz Júnior AC. Método SARAH: reabilitação baseada na família e no contexto da criança com des de maior complexidade de execução e nas crianças entre um e três anos. Porém, a maior parte da amostra exibiu algumas defasagens nas noções desse estágio cognitivo, com grande variabilidade de condutas que mostraram uma construção simultânea de mais de um subestágio.

As crianças com SD podem necessitar de maior tempo para desenvolver a sua primeira etapa cognitiva. Para compreender o "eu", os objetos, o espaço, a causalidade física e o tempo é preciso agir, locomover-se e manipular aquilo que as rodeiam. É transformando os objetos e o meio que o mundo se conforma e a inteligência avança. Dessa forma, uma redução nas experiências motoras pode atrapalhar a adaptação da criança e o seu processo de desenvolvimento cognitivo. Foi possível estabelecer essa associação principalmente nos sujeitos mais novos da amostra. Portanto, acreditamos que o maior tempo de experiências motoras e as maiores possibilidades de interações com diferentes contextos, assim como a maior maturação neurológica, tenham contribuído na evolução do desenvolvimento das crianças mais velhas.

lesão cerebral. São Paulo: Santos Editora, 2008. p. 17-52.

4. Papalia DE, Olds SW. Desenvolvimento humano. Porto Alegre: Artmed, 2000.

5. Gallahue DL, Ozmun JC. Compreendendo o desenvolvimento motor: bebês, crianças, adolescentes e adultos. São Paulo: Phorte, 2005.

6. Piaget J. Seis estudos de Psicologia. Rio de Janeiro: Forense Universitária, 1993.

7. Macedo L. Piaget e a nossa inteligência. Pátio: Revista Pedagógica, 1997; 1(1):10-3.

8. Gusman S, Torre CA. Fisioterapia na Síndrome de Down. In: Schwartzman JS et al. Síndrome de Down. São Paulo: Mennon, 1999. p. 167-205. 
9. Zausmer E. Estimulação precoce do desenvolvimento. In: Pueschel SM (Orgs.). Síndrome de Down: guia para pais e educadores. Campinas: Papirus, 2007. p. 115-26.

10. Sarro KJ, Salina ME. Estudo de alguns fatores que influenciam no desenvolvimento das aquisições motoras de crianças portadoras de Síndrome de Down em tratamento fisioterápico. Fisioter Mov. 1999;8(1):93-106.

11. Palisano RJ, Walter SD, Russell DJ, Rosenbaum PL, Gémus M, Galuppi BE et al. Gross motor function of children with Down Syndrome: creation of motor growth curves. Arch Phys Med Rehabil. 2001;82(4):494-500.

12. Delval J. Introdução à Prática do Método Clínico: descobrindo o pensamento das crianças. Porto Alegre: Artmed, 2002.

13. Piaget J. A construção do real na criança. São Paulo: Ática, 2006.

14. Piaget J. O nascimento da inteligência na criança. Rio de Janeiro: LTC Editora, 2008.

15. Carraher TN. O Método Clínico: usando os exames de Piaget. São Paulo: Cortez Editora, 1989.

16. Uzgiris IC, Hunt JMc. Assessment in infancy: Ordinal scales of psychological development. Urbana, USA: University of Illinois Press, 1978.

17. Pueschel SM. Características físicas da criança. In: Pueschel SM (Orgs.). Síndrome de Down: guia para pais e educadores. Campinas: Papirus, 2007. p. 77-83.

18. Silva NLP, Dessen MA. Síndrome de Down: etiologia, caracterização e impacto na família. Interação em Psicologia. 2002;6(2):167-76.

19. Acredolo L. Individual differences in infant spatial displacement. In: Colombo J, Fagen J (Eds.). Individual differences in infancy: Reliability, stability, prediction. Hillsdale: Erlbaum, 1990. p. 321-40.

20. Bell MA, Fox NA. Individual differences in object permanence performance at 8 months: locomotor experience and brain electrical activity. Dev Psychobiol. 1997;31(4):287-97.

21. Kermoian R, Campos JJ. Locomotor experience: a facilitator of spatial cognitive development. Child Dev. 1988;59(4):908-17.
22. Alton S. Fine Motor Skills in children with Down Syndrome: Information Sheet. Northern Ireland: Down Syndrome Association, 2005.

23. Ramalho CMJ, Pedromônico MR, Perissinoto J. Síndrome de Down: avaliação do desempenho motor, coordenação e linguagem (entre dois e cinco anos). Tem Desenvol. 2000;9(52):11-4.

24. Neto FR. Manual de avaliação motora. Porto Alegre: Artmed, 2002.

25. Campos D, Santos DCC. Controle postural e motricidade apendicular nos primeiros anos de vida. Fisioter Mov. 2005;18(3):71-7.

26. Rochat P. Object manipulation and exploration in 2 to 5 month-old infants. Dev Psychol. 1989;25(6):871-84.

27. Thelen E, Corbetta D, Spencer JP. Development of reaching during the first year: role of movement speed. J Exp Psychol Hum Percept Perform. 1996;22(5):1059-76.

28. Samsom JF, Groot L. The influence of postural control on motility and hand function in a group of high risk preterm infants at 1 year of age. Early Hum Dev. 2000;60(2):101-13.

29. Deliberato D, Gonçalves VMG. Aspectos do desenvolvimento da percepção visual. Tem Desenvol. 2003;12(67):5-10.

30. Piaget J, Inhelder B. A psicologia da criança. Rio de Janeiro: Difel, 2003.

31. Schwartzman JS. Alterações clínicas. In: Schwartzman JS. Síndrome de Down. São Paulo: Mennon, 1999. p.82-127.

32. John FM, Bromham NR, Woodhouse JM, Candy TR. Spatial vision deficits in infants and children with Down Syndrome. Invest Ophthalmol Vis Sci. 2004;45(5):1566-72.

33. Ministério da Educação. Saberes e práticas da inclusão: dificuldades de comunicação e sinalização - deficiência visual. Brasília: MEC/Secretaria de Educação Especial, 2006.

34. Virji-Babul N, Kerns K, Zhou E, Kapur S, Shiffrar M. Perceptual-motor deficits in children with Down syndrome: implications for intervention. Downs Syndr Res Pract. 2006;10(2): 74-82.

Recebido em 02/02/10 Modificado em 06/07/10 Aceito em 12/08/10 